\title{
Nanocellulose Produced from Rice Hulls and its Effect on the Properties of Biodegradable Starch Films
}

\author{
Pedro Nascimento ${ }^{a}$, Renan Marim ${ }^{a}$, Gizilene Carvalho ${ }^{b}$ and Suzana Mali ${ }^{a}$ \\ ${ }^{a}$ Department of Biochemistry and Biotechnology, State University of Londrina - UEL, \\ Rodovia Celso Garcia Cid, Pr 445 Km 380, CEP 86057-970, Londrina, PR, Brazil. \\ ${ }^{b}$ Department of Chemistry, State University of Londrina - UEL, \\ Rodovia Celso Garcia Cid, Pr 445 Km 380, CEP 86057-970, Londrina, PR, Brazil..
}

Received: July 22, 2015; Revised: September 30, 2015; Accepted: November 26, 2015

\begin{abstract}
Rice hull is a residue from agro-industry that can be used to produce nanocellulose. We produced nanocellulose from rice hulls through bleaching (with a $5 \% \mathrm{NaOH}$ solution followed by a peracetic acid solution) and acid hydrolysis at a mild temperature $\left(45^{\circ} \mathrm{C}\right)$ followed by ultrasonication. We investigated the microstructure, crystallinity and thermal stability of these materials and studied their effects on the properties of starch films. After bleaching, the compact structure around the cellulosic fibers was removed, and the lignin content of the residue decreased from 7.22 to $4.22 \%$. The obtained nanocellulose presented a higher crystallinity (up 70\%), higher thermal stability than the raw material and lignin contents below $0.35 \%$. The nanocellulose formed interconnected webs of tiny fibers $(<100 \mathrm{~nm}$ in diameter), which decreased the opacity, water vapor permeability and improved the mechanical properties when added as reinforcement in the starch films.
\end{abstract}

Keywords: Agro-industrial residue, Nanofibrils, microstructure

\section{Introduction}

The research and development of materials fabricated from renewable sources has been a focus of the scientific community in the $21^{\text {st }}$ century. This research includes the development of novel, green, bio-based and degradable materials from natural sources for various engineering applications ${ }^{1-4}$.

The world rice harvest is estimated as 500 million tons per year, and rice hull $(\mathrm{RH})$ is the major byproduct generated during the rice milling process. Rice hulls represents approximately $20 \%$ of the dry weight of the rice harvest ${ }^{5}$. Rice hulls contain 36-40 g/100 g cellulose and 12-19 g/100 g hemicelluloses. Ash represents approximately $12 \mathrm{~g} / 100 \mathrm{~g}$, which is primarily silica $(80-90 \mathrm{~g} / 100 \mathrm{~g})^{6,7}$.

Recently, agro-industrial solid residues with high cellulose content (rice hulls) have been used in cellulose and nanocellulose production ${ }^{4,8}$. Two types of nanocellulose can be isolated from a cellulosic source: nanocrystals, and nanofibrils. Nanocrystals have a crystalline structure, and nanofibrils are fibrillar units containing both amorphous and crystalline regions. Nanofibrils can create entangled networks with diameters less than $100 \mathrm{~nm}$. They also possess attractive properties such as high strength, flexibility and high aspect ratio (length to diameter ratio) ${ }^{9-10}$.

Cellulose nanofibrils have been prepared from a variety of sources using several mechanical processes ${ }^{11-13}$ such as ultrasonication ${ }^{14}$. Chemical or enzymatic treatments can be employed before or after the mechanical process ${ }^{9,10,15}$. Paschoal et al. ${ }^{16}$ obtained nanofibrillated cellulose from oat hulls using bleaching with peracetic acid, acid hydrolysis

*e-mail: smali@uel.br at a mild temperature $\left(45^{\circ} \mathrm{C}\right)$ followed by ultrasonication. They reported the use of a totally chlorine-free technique (TCF) to extract and bleach cellulose from oat hulls. In the present work we propose the use of rice hulls for obtaining cellulose nanofibrils employing peracetic acid as a more environmentally friendly bleaching agent.

Cellulose nanofibrils are used as a reinforcing material in starch films to improve their mechanical and barrier properties ${ }^{17,18}$. However, their effect depends on the cellulose source and extraction method m,20. $^{1920}$.

We investigated the microstructure, crystallinity and thermal stability of cellulose nanofibrils obtained from rice hulls using bleaching and acid hydrolysis at a mild temperature $\left(45^{\circ} \mathrm{C}\right)$ followed by ultrasonication. We analyzed the effects of nanofibrils addition on the properties of starch films produced by extrusion.

\section{Experimental}

\subsection{Materials}

Unpurified rice hulls $(\mathrm{RH})$ were kindly supplied by HT-Nutri (Camaquã, RS, Brazil). The residue was dried $\left(12-14 \mathrm{~h}\right.$ ) at $45^{\circ} \mathrm{C}$ in an air circulation oven (Marconi MA 415 - Piracicaba-Brazil) and milled (IKA-A 11 Basic Mill - Germany) to yield particles $<0.30 \mathrm{~mm}$.

\subsection{Methods}

\subsubsection{Chemical composition}

The centesimal composition of the residue (proteins, lipids, moisture and ash) was determined following methods adapted by the Association of Official Analytical Chemists 
$(\mathrm{AOAC})^{21}$. The total carbohydrate content was calculated from the difference. All experiments were run in triplicate.

The total dietary fiber and soluble and insoluble fractions were determined according to AACC method 32-0 $7^{22}$. Cellulose content was determined by the Updegraff method ${ }^{23}$, and the lignin content was determined by the Technical Association of the Pulp and Paper Industry (TAPPI T222 om-88) method $^{24}$. The hemicelluloses were calculated by taking the insoluble dietary fiber (IDF) minus the cellulose plus the lignin content because the insoluble IDF fraction of cereal is composed of cellulose, hemicelluloses and lignin ${ }^{25}$.

\subsubsection{Bleaching of the rice hulls}

The bleaching of the rice hulls was performed in two stages. The first stage was an alkaline pre-treatment ${ }^{26}$. Rice hulls $(20 \mathrm{~g}$ ) were immersed in $200 \mathrm{ml}$ of sodium hydroxide $(\mathrm{NaOH}) 5 \%(\mathrm{w} / \mathrm{v})$ at $90^{\circ} \mathrm{C}$ for 60 min under constant stirring. The material was washed with distilled water until it reached a neutral $\mathrm{pH}$ and was dried at $40^{\circ} \mathrm{C}$ for $24 \mathrm{~h}$.

In the second stage, approximately $20 \mathrm{~g}$ of the material from the alkaline pre-treatment was dispersed in $250 \mathrm{~mL}$ of a peracetic acid solution (50\% acetic acid (Synth - Brazil), $38 \%$ hydrogen peroxide (Synth - Brazil) and $12 \%$ distilled water) at $60^{\circ} \mathrm{C}$ and vigorously stirred for $24 \mathrm{~h}^{16}$. The fibers were vacuum filtered, washed with distilled water until the $\mathrm{pH}$ value was between 6 and 7 and dried at $35^{\circ} \mathrm{C}$ for $12-24 \mathrm{~h}$ in an air-circulating oven (Tecnal - São Paulo-Brazil). The bleached rice hull was labeled as RHB.

\subsubsection{Preparation of the cellulose nanofibrils from rice hulls}

Approximately $10 \mathrm{~g}$ of bleached rice hulls were dispersed in $100 \mathrm{~mL}$ of $63.7 \%(\mathrm{w} / \mathrm{v})$ sulfuric acid (Synth - Brazil) at $45^{\circ} \mathrm{C}$ and vigorously stirred for 1 or $2 \mathrm{~h}$. Cold distilled water $(200 \mathrm{~mL})$ was added to stop the reaction. The sulfuric acid was partially removed from the resulting suspension through centrifugation at $10,000 \mathrm{rpm}$ for $10 \mathrm{~min}$. The non-reactive sulfate groups were removed using centrifugation followed by dialysis in tap water with a cellulose membrane (Sigma-Aldrich: D9402) until the $\mathrm{pH}$ value was between 6 and 7. Dialysis was performed in running distilled water for 3-4 days. The neutral suspension was ultrasonicated (Ultrasonic Processor - Fisher Scientific - USA) for $15 \mathrm{~min}$, two drops of chloroform were added and then the suspension was stored in a refrigerator. The cellulose nanofibrils samples were labeled RHNF1h or RHNF2h, depending on the extraction time. A $50 \mathrm{~mL}$ aliquot was dried at $35^{\circ} \mathrm{C}$ for $12 \mathrm{~h}$ in an air-circulating oven (Tecnal - São Paulo-Brazil) for X-ray diffraction, Fourier transform infrared spectroscopy and thermogravimetric analyses.

\subsubsection{Cellulose nanofibril characterization}

\subsubsection{Scanning electron microscopy (SEM)}

SEM analyses were performed with a FEI Quanta 200 microscope (Oregon, USA) to observe the morphology of RH and RHB. The dried samples were mounted for visualization on bronze stubs using double-sided tape. The surfaces were coated with a thin gold layer $(40-50 \mathrm{~nm})$. All samples were examined using an accelerating voltage of $30 \mathrm{kV}$.

\subsubsection{Transmission electron microscopy (TEM)}

The suspensions of RHNF1h and RHNF2h were observed by TEM using a FEI-TECNAI 12 transmission electron microscope (Oregon - USA) with an acceleration voltage of $80 \mathrm{kV}$. A droplet of diluted suspension was deposited on a carbon coated grid and allowed to dry. The grid was stained with a $1.5 \%$ solution of uranyl acetate and dried at room temperature.

\subsubsection{X-ray diffraction (XRD)}

The samples were finely powdered (particles $<0.149 \mathrm{~mm}$ ). The analysis was performed using a PANalytical X'Pert PRO MPD diffractometer (Netherlands) with copper K $\alpha$ radiation $(\lambda=1.5418 \AA$ ) $)$ under the operational conditions of $40 \mathrm{kV}$ and $30 \mathrm{~mA}$. All assays were performed with a ramp rate of $1 \% \mathrm{~min}$. The relative crystallinity index $(\mathrm{CI})$ was calculated using the Segal et al., method ${ }^{27}$ : CI $(\%)=\left(\left[\left(\mathrm{I}_{002}-\mathrm{I}_{\mathrm{am}}\right)\right] / \mathrm{I}_{002}\right) * 100$, in which $\mathrm{I}_{002}$ is the intensity of the 002 peak (at approximately $2 \theta=20-22^{\circ}$ ) and $I_{a m}$ is the intensity corresponding to the peak at $2 \theta=18^{\circ}$.

\subsubsection{Fourier Transform Infrared (FT-IR) Spectroscopy}

The pulverized and dried samples were then mixed with potassium bromide and compressed into tablets. The FT-IR analyses were performed with a Shimadzu FT-IR - 8300 (Japan), with a spectral resolution of $4 \mathrm{~cm}^{-1}$ and a spectral range of $4000-500 \mathrm{~cm}^{-1}$.

\subsubsection{Thermogravimetric analysis (TGA)}

Thermogravimetric analysis (TGA 50 - Shimadzu - Japan) was performed under a nitrogen atmosphere $\left(50 \mathrm{~mL} \mathrm{~min}^{-1}\right)$. The samples (approximately $10 \mathrm{mg}$ ) were heated from 30 to $600^{\circ} \mathrm{C}$ at a heating rate of $10^{\circ} \mathrm{C} / \mathrm{min}$. The weight loss (\%) was evaluated by measuring the residual weight at $600^{\circ} \mathrm{C}$.

\subsubsection{Differential scanning calorimetry (DSC)}

The DSC analyses were performed on a Shimadzu DSC 60 (Japan) calorimeter. Approximately $3.0 \mathrm{mg}$ of each sample were placed in platinum containers and heated from 30 to $450^{\circ} \mathrm{C}$ at a heating rate of $5^{\circ} \mathrm{C} / \mathrm{min}$ in a helium atmosphere.

\subsubsection{Films manufactured by extrusion}

The films were formulated with cassava starch $(72.5 \%$ $\mathrm{w} / \mathrm{w})$ and glycerol $(25.0 \% \mathrm{w} / \mathrm{w})$ as the plasticizer. Rice hull $(\mathrm{RH})$, bleached rice hull (RHB) or cellulose nanofibrils (RHNF1h) were added as reinforcing agents to film formulations $(2.5 \% \mathrm{w} / \mathrm{w})$. RH and RHB were added as powders to the starch-glycerol mixture. RHNF1h was added in a wet state ( $20 \%$ moisture) to the starch-glycerol mixture. A control film was produced without any reinforcing agent at $75 \%$ $\mathrm{w} / \mathrm{w}$ of starch and $25 \% \mathrm{w} / \mathrm{w}$ glycerol.

All film formulations were stored for $1 \mathrm{~h}$ after manual mixing. The mixture was fed to the extruder (BGM EL-25, single screw, $25 \mathrm{~mm}$ screw diameter, and $700 \mathrm{~mm}$ screw length) for the first time to obtain pellets of gelatinized material. These pellets were re-extruded for better homogenization. The second batch of pellets was fed to the extruder for film manufacturing by blowing $(50 \mathrm{~mm}$ blowing matrix diameter). Extrusion temperatures were (from feeding zone 
to die): $120 / 130 / 120 / 120^{\circ} \mathrm{C}$ for the pellet formation step and $120 / 130 / 120 / 130^{\circ} \mathrm{C}$ for the blowing step. Screw rotation was constant at $35 \mathrm{rpm}$.

\subsubsection{Film characterization}

All film samples were conditioned at $25^{\circ} \mathrm{C}$ and $58 \% \mathrm{RH}$ (over a saturated solution of sodium bromide $-\mathrm{NaBr}$ ) for $7 \mathrm{~d}$ before testing. Thickness was determined using a manual micrometer with $\pm 0.1 \mu \mathrm{m}$ accuracy (Mitutoyo, Brazil), and calculated as the average of 10 measurements taken at random positions on the film. The film density was determined directly from the film weight and dimensions (volume). Reported values were the average of ten calculations.

Opacity was determined according to the Hunterlab method reported by Sobral ${ }^{28}$ with a BYK Gardner colorimeter (Maryland-USA) operating in the reflectance mode. The opacity (Y) of the samples was calculated as the relationship between the opacity of each sample on the black standard $\left(\mathrm{Y}_{\mathrm{b}}\right)$ and the opacity of each sample on the white standard $\left(\mathrm{Y}_{\mathrm{w}}\right): \mathrm{Y}=\left(\mathrm{Y}_{\mathrm{b}} / \mathrm{Y}_{\mathrm{w}}\right) * 100$. The results were reported as the percentage of opacity. All tests were performed in triplicate.

Water vapor permeability (WVP) was performed according to a modified ASTM E96-00 method ${ }^{29}$. Film samples were sealed over a $60 \mathrm{~mm}$ circular opening of a permeation cell containing calcium chloride $(0 \% \mathrm{RH}$ inside the cell). The set was placed inside a desiccator containing saturated sodium chloride solution $(75 \% \mathrm{RH}$ outside the cell) to create a $75 \% \mathrm{RH}$ gradient across the film. All tests were performed in triplicate.

Mechanical properties were determined using a TA.TX2i Stable Micro Systems texture analyzer (Surrey - England) in accordance with ASTM D-882-9130. Ten sample strips $(25.4 \times 100.0 \mathrm{~mm})$ of each formulation were clamped between pneumatic grips $(50 \mathrm{~mm}$ initial distance between the grips) and distended at $50 \mathrm{~mm} \cdot \mathrm{min}^{-1}$. The force (N) and deformation $(\mathrm{mm})$ were reported to determine the tensile strength (MPa), elongation (\%) and Young's modulus (MPa).

\subsubsection{Statistical analysis}

Tukey's test $(\mathrm{p} \leq 0.05)$ was employed for mean comparison and was performed using STATISTICA 7.0 (Statsoft, Oklahoma).

\section{Results and Discussion}

The original lignin content of RH $(7.24 \pm 0.59 \%)$ decreased in all samples. The lignin content of RHB, RHNF1h and RHNF2h were $4.22 \pm 0.27,0.12 \pm 0.45$ and $0.32 \pm 0.43 \%$, respectively. The results demonstrated that bleaching followed by acid hydrolysis were effective for cellulose purification.

\subsection{Morphological analyses (SEM and TEM) of rice hulls after bleaching and acid hydrolysis}

The morphology of the longitudinal surface of the fibers before and after bleaching is shown in Figure 1. The original fiber forms a well-organized and compact structure (Figure 1a) with the nonfibrous components (hemicellulose and lignin). The corrugated outer epidermis containing silica deposited on the surface of the epidermal tissue ${ }^{31,32}$ can be observed.

After the alkaline pre-treatment (Figure 1b), the fiber surface was less compact and its original structure was disorganized. This result indicated a partial removal of the outer non-cellulosic layer composed of hemicelluloses and lignin. According to Patel et al. ${ }^{31}$, alkali treatment of rice hull cannot destroy its inherent structure. $\mathrm{NaOH}$ treatment removes the silica and leaves the fibrous organic material.

After the $\mathrm{NaOH}$ pre-treatment and the peracetic acid treatment (Figure 1c), the fiber bundles were removed from the lignocellulosic complex. These bundles become individualized (Figure 2b), and the microfibrils are visualized. In plant cells, lignin and hemicelluloses are deposited between the cellulosic microfibrils forming an interrupted lamellar structure ${ }^{15,16}$. Bleaching agents can remove these non-cellulosic components.

The suspensions resulting from the acid hydrolysis were stable. There was no sedimentation when they were stored at room temperature for extended periods of time. TEM micrographs of the rice hulls nanofibers are depicted in Figure 2, revealing the homogeneity and nanometric dimensions of these materials.

The hydrolysis time did not affect the morphological properties of the cellulose nanofibers from rice hulls (Figure 2). The nanocellulose we obtained contained interconnected webs of tiny fibers with diameters in the nanometric

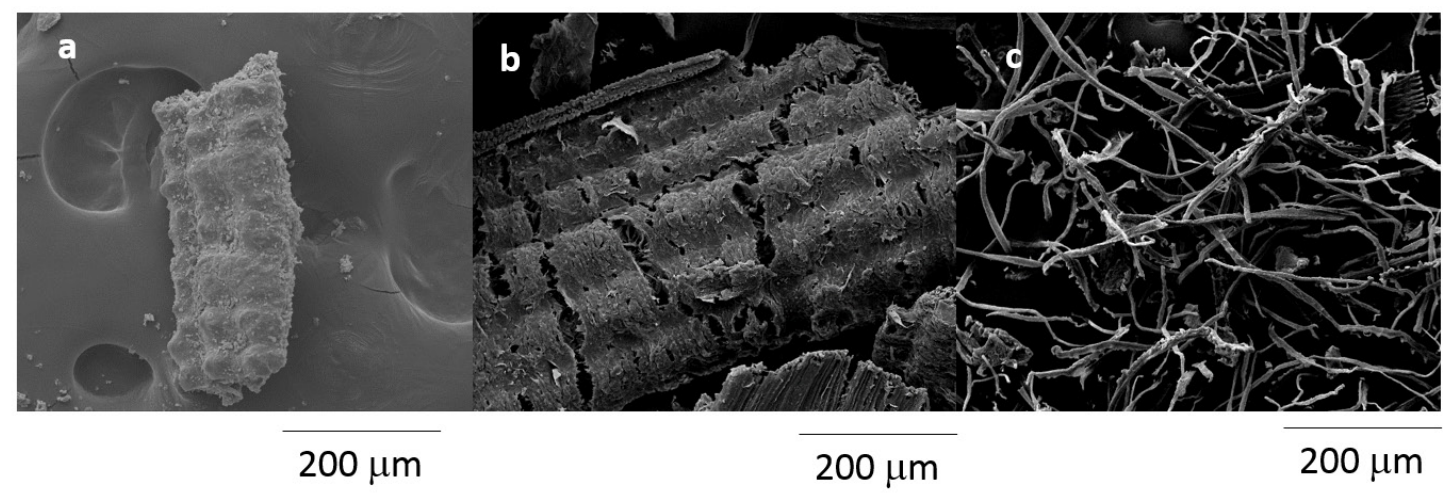

Figure 1. Micrographs obtained using SEM: raw rice hulls (a), rice hulls pre-treated with $\mathrm{NaOH}$ (b) and rice hulls treated with $\mathrm{NaOH}$ followed by peracetic acid. 


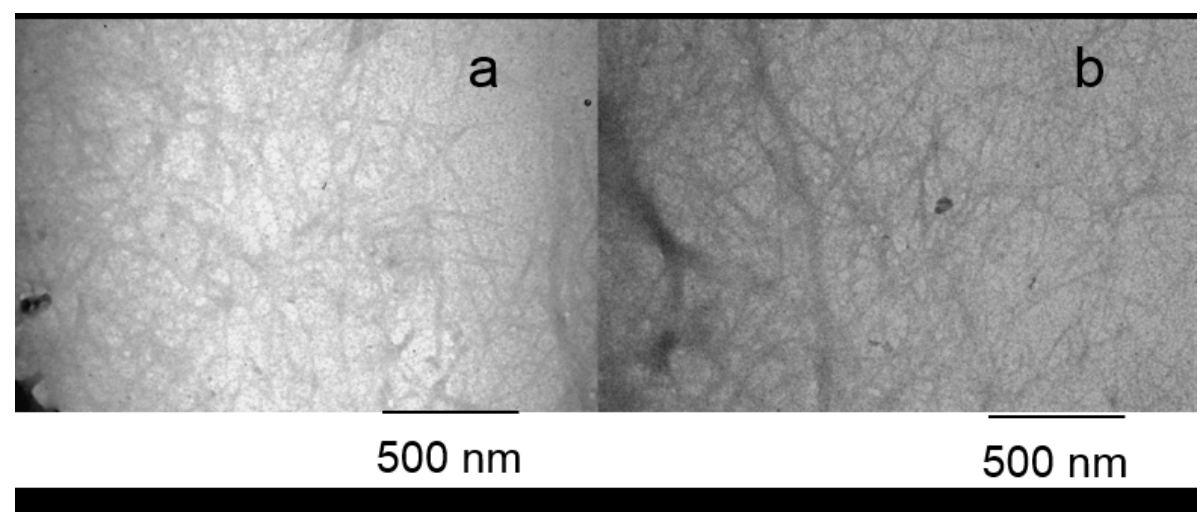

Figure 2. Micrographs obtained using TEM of the cellulose nanofibers from rice hulls: extraction at $1 \mathrm{~h}$ (a), and $2 \mathrm{~h}$ (b).

scale $(<100 \mathrm{~nm})$ and lengths of several micrometers. These nanofibers possess a high aspect ratio. Paschoal et al., ${ }^{16}$ also obtained nanocellulose with similar characteristics using peracetic acid. Peracetic acid is a strong oxidizing agent with excellent bleaching properties. It is an environmentally safe alternative for bleaching because it is a chlorine free (TCF) process that results in less damage to the fiber ${ }^{16,33-35}$.

\section{$3.2 X$-ray diffraction of rice hulls after bleaching and acid hydrolysis}

The X-ray diffraction patterns of RH, RHB, RHNF1h and RHNF2h are depicted in Figure 3. These patterns are typical of semicrystalline materials with an amorphous broad hump and crystalline peaks. Cellulose was responsible for the crystalline structure, whereas hemicellulose and lignin are amorphous in nature ${ }^{36}$. In the RH pattern, one peak was observed at $22^{\circ}$. The RHB, RHNF1h and RHNF2h peaks were observed at $16^{\circ}, 22^{\circ}$ and $34^{\circ}$. These peaks are characteristic of type I cellulose ${ }^{16,36}$ (Figure 3). Both the bleached and hydrolyzed samples did not exhibit any variation in their polymorph type compared with the original fibers. The peaks become more defined after chemical treatment.

The RH sample demonstrated a lower crystallinity index $(\mathrm{CI}=52 \%)$ than the bleached (RHB, CI $=68 \%)$ and hydrolyzed (RHNF1h, CI $=75 \%$ and $\mathrm{RHNF} 2 \mathrm{~h}, \mathrm{CI}=72 \%$ ) samples. The lower CI of the RH sample occurred because of the reduction and removal of the amorphous, non-cellulosic compounds. This removal was induced by bleaching and acid hydrolysis. According to Abraham et al. ${ }^{15}$, lignin removal results in an increase in the crystallinity index. The $\mathrm{CI}$ values of the hydrolyzed samples were nearly identical, and these results were consistent with the TEM analysis. The identical morphology was observed for RHNF1h and RHNF2h.

\subsection{Fourier Transform Infrared (FT-IR) Spectroscopy}

The FT-IR spectra of RH, RHB, RHNF1h and RHNF2h are depicted in Figure 4. All of the spectra displayed a wide absorption band corresponding to $\mathrm{O}-\mathrm{H}$ stretching between 3400 and $3200 \mathrm{~cm}^{-1}$. This band indicates H-bonding interactions in these materials. The peaks observed at $2900 \mathrm{~cm}^{-1}$ correspond to $-\mathrm{C}-\mathrm{H}$ stretching. Figure 4 demonstrates $\mathrm{H}-\mathrm{C}-\mathrm{H}$ and $-\mathrm{C}-\mathrm{O}-\mathrm{H}$ conjugated bending vibrations in all spectra.

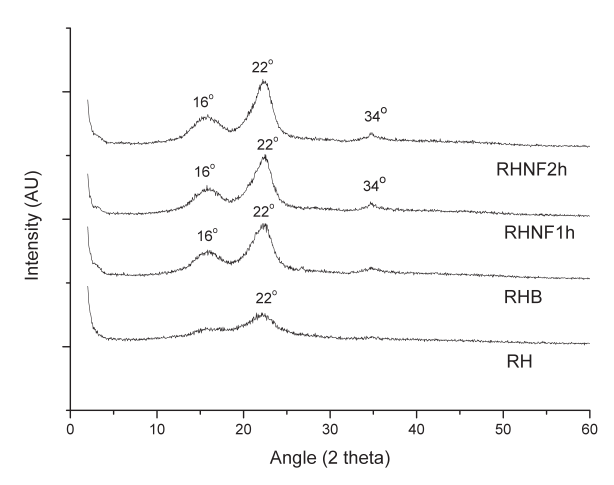

Figure 3. X-ray diffractograms of RH, RHB, RHNF1h and RHNF2h.

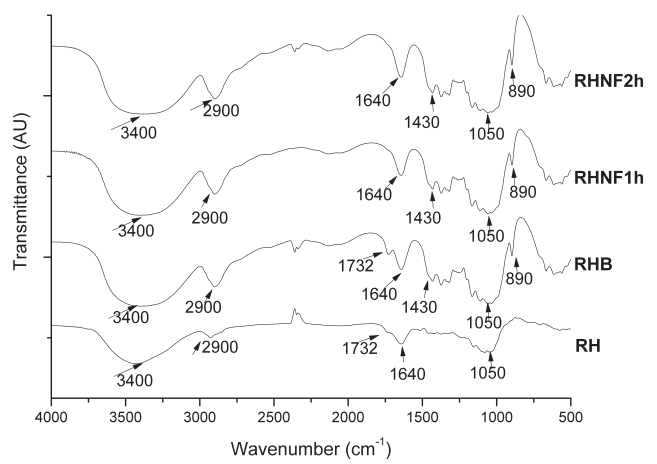

Figure 4. FT-IR spectra of RH, RHB, RHNF1h and RHNF2h.

A shoulder was observed at approximately $1700 \mathrm{~cm}^{-1}$ in the spectra of the RH and RHB samples (Figure 4). This feature represents the acetyl or uronic ester groups of the hemicelluloses ${ }^{2,36}$. We observed the disappearance of this shoulder in the RHNF1h and RHNF2h samples, indicating the removal of hemicelluloses from these samples.

The shoulder observed at approximately $1700 \mathrm{~cm}^{-1}$ (Figure 4) in the spectra corresponds may also be attributed to the presence of $\mathrm{C}=\mathrm{O}$ linkage ${ }^{15}$, which is characteristic of lignin and hemicellulose in these samples. 
Bands were observed at approximately $1640 \mathrm{~cm}^{-1}$ for all samples. These bands are associated with the angular $\mathrm{O}-\mathrm{H}$ bending of water molecules. According to Abraham et al. ${ }^{15}$, the water adsorbed in the cellulose molecules is difficult to extract because of the cellulose-water interaction.

The band at $1650 \mathrm{~cm}^{-1}$ may be assigned to water, but could also be attributed to the aromatic $\mathrm{C}=\mathrm{C}$ stretch of the aromatic ring in the lignin ${ }^{37}$. The contribution from the absorbed water predominates in the case of RHB, RHNF1h and RHNF2h. However, in the raw rice hull (RH), this band could be attributed to the lignin.

Bands at 1430 and $890 \mathrm{~cm}^{-1}$ can be observed in the FT-IR spectra of RHB, RHNF1h and RHNF2h (Figure 4). These bands are typical of pure cellulose $\mathrm{e}^{2,36}$. The band at $890 \mathrm{~cm}^{-1}$ represents $\mathrm{C}-\mathrm{O}-\mathrm{C}$ stretching vibrations of the characteristic $\beta(1 \rightarrow 4)$-glycosidic linkage ${ }^{36}$.

According to Sun et al. ${ }^{37}$, the $\mathrm{C}-\mathrm{O}-\mathrm{C}$ pyranose ring skeletal vibration occurs in the region of $1076-1023 \mathrm{~cm}^{-1}$. In our work, this band appeared in all samples (Figure 4) and was more intense in RHB, RHNF1h and RHNF2h.

The differences between the spectra of $\mathrm{RH}$ and the other samples suggested that these samples have higher cellulose content than the raw sample and are almost pure cellulose.

\subsection{Thermogravimetric analysis (TGA)}

The curves obtained from TGA analysis are shown in Figure 5. A small weight loss $(<10 \%)$ was found in the range of $50-100^{\circ} \mathrm{C}$ because of the evaporation of water or other low molecular weight compounds from the materials.
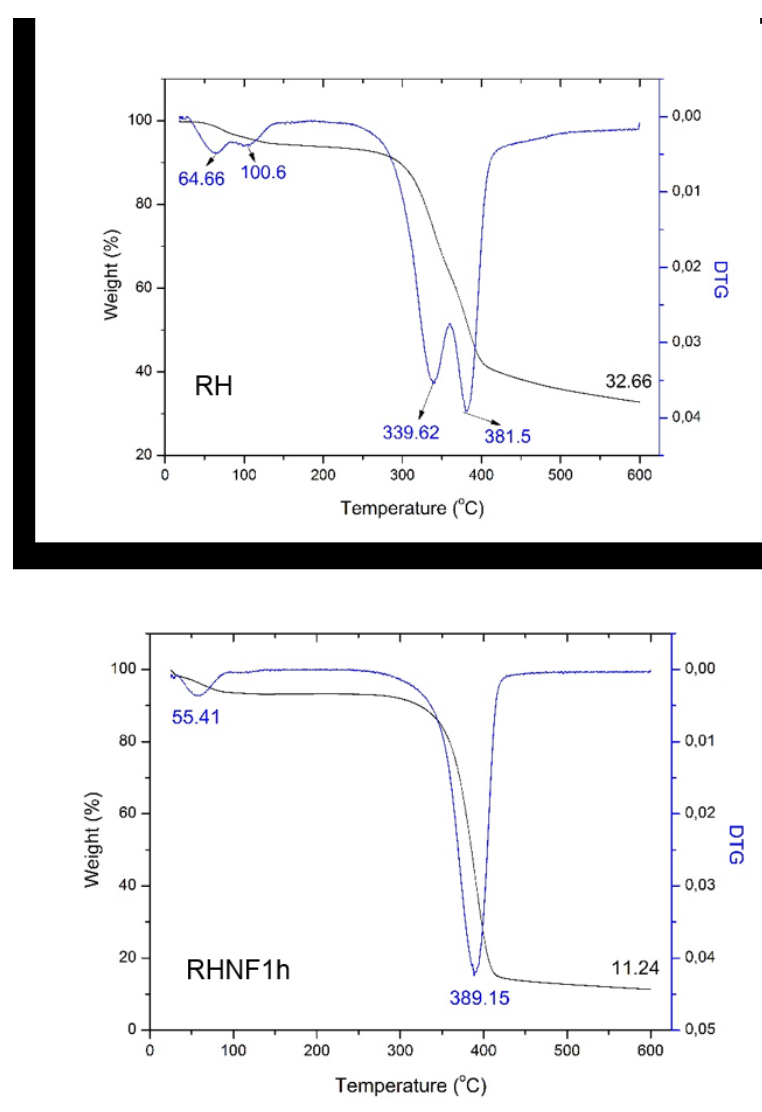

The maximum degradation temperature (Figure 5) was higher for the hydrolyzed samples (RHNF1h and RHNF2h) compared to the raw material $(\mathrm{RH})$ and bleached sample (RHB). This result indicated that the nanofibers extracted from rice hulls had increased the thermal stability. Our results were similar to those of Abraham et al., ${ }^{17}$ who produced nanofibrillated cellulose from banana, pineapple leaf and jute fibers using alkaline treatment followed by steam explosion and acid hydrolysis. Paschoal et al., ${ }^{16}$ also reported that nanofibers extracted from oat hulls possessed a higher thermal stability than the raw material. Nanocellulose obtained from natural fibers demonstrate a higher thermal stability than the cellulose present in untreated lignocellulosic fibers. This increased stability is because the hydrolyzed samples are more crystalline than the raw material, and a greater crystalline structure requires a higher degradation temperature ${ }^{38}$.

\subsection{Differential scanning calorimetry}

In all the thermograms, from $50^{\circ} \mathrm{C}$ to $125^{\circ} \mathrm{C}$, an endothermic peak was present because of water evaporation (Figure 6). RHNF1h and RHNF2h demonstrated sharp endothermic peaks at $347^{\circ} \mathrm{C}$ (Figure 6) that may represent the melting of the crystalline fraction of these samples. RHB demonstrated a less intense peak at the identical temperature and the raw material ( $\mathrm{RH})$ demonstrated an endothermic peak at $328^{\circ} \mathrm{C}$ (Figure 6). Morán et al., ${ }^{39}$ reported that commercial cellulose contained endothermic peaks related to its crystal melting
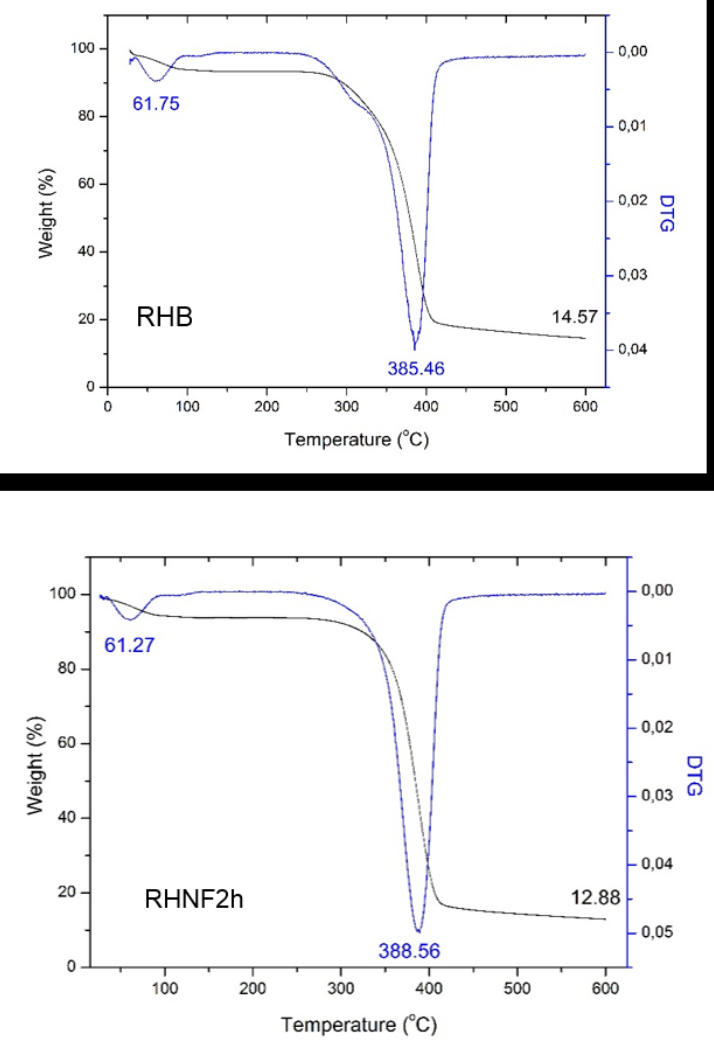

Figure 5. TGA curves of RH, RHB, RHNF1h and RHNF2h. 
at $330^{\circ} \mathrm{C}$ and that a decrease in the position of the peak indicates an increase in the amount of amorphous cellulose. We report similar results for RHB, RHNF1 h and RHNF2 $h$ (higher crystallinity index) compared to $\mathrm{RH}$.

\subsection{Film characterization}

The surfaces of the extruded films were examined using SEM (Figure 7). The control film, the RH-film and the RHB-film had rough surfaces, without any fibers of agglomeration. The RHNF-film demonstrated a more homogeneous and smooth surface (Figure 7d) than the other samples. The nanofibers were well dispersed and covered by the matrix, suggesting that the introduction of cellulose nanofibers into the starch-glycerol films resulted in improved adhesion between the nanofibers and the polymer matrix.

The densities of the starch films were not significantly (Tukey test, $\mathrm{p} \leq 0.05$ ) affected by the addition of fiber (Table 1). The opacity of the films decreased with the addition of RHNF1h (Table 1). Transparency is an indirect measure of the size and dispersion of cellulose nanofibers in the film matrix. The transparency decreases because of increased light scattering ${ }^{20}$ when the cellulose reinforcement is not nanoscale or is aggregated.

The WVP for the starch films decreased with the addition of nanofibers (Table 1). This effect was not observed for the addition of RH or RHB. Kaushik et al. ${ }^{20}$ observed the identical effect after the addition of cellulose nanofibrils from wheat straw on starch films. They also reported that the WVP decrease in starch films is related to a reduction in the diffusion coefficient because of the fibers. Fiber agglomeration, a reduction in matrix homogeneity and detrimental effects to the barrier properties occurs when the nanofiber loading is above $10 \%$. In this work, we used a nanofiber addition of $2.5 \%$. This loading improved film barrier properties. However, the addition of RH and RHB did not affect the WVP of the films. This result may be related to the less homogeneous film matrix that was observed in the SEM images.

The mechanical properties of the starch films were affected by the addition of fibers (Table 1). The addition of $\mathrm{RH}$ and RHB resulted in a decrease in tensile strength. This decrease may be associated with the non-homogeneity of the film matrix. The addition of RHNF1h resulted in an increase in tensile strength and elongation, and a decrease in Young's modulus.

Some authors have suggested that the addition of nanofibers may reinforce starch films matrices and improve tensile strength, indicating efficient bonding and stress transfer from the matrix to the fiber ${ }^{20}$.

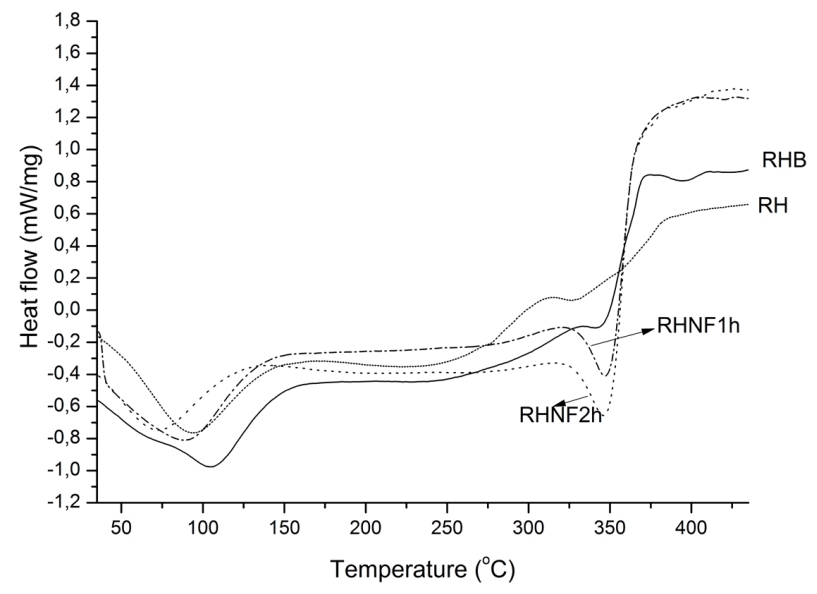

Figure 6. DSC curves of RH, RHB, RHNF1h and RHNF2h.

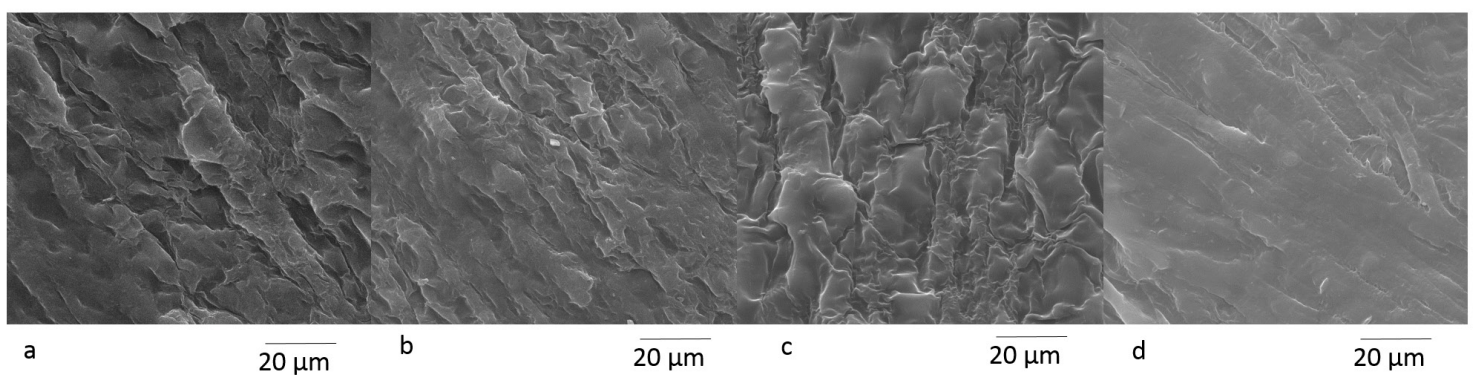

Figure 7. SEM images of the control film (a), the RH-film (b), the RHB-film (c) and the RHNF-films (d). 
Table 1. Density, opacity, water vapor permeability (WVP) and mechanical properties of starch-glycerol films reinforced with RH, RHB and RHNF1h.

\begin{tabular}{|c|c|c|c|c|c|c|}
\hline \multirow[t]{2}{*}{ Sample film } & \multirow[t]{2}{*}{ Density $\left(\mathrm{g} / \mathrm{cm}^{3}\right)$} & \multirow[t]{2}{*}{ Opacity } & \multirow{2}{*}{$\begin{array}{c}\mathrm{WVP}_{\mathrm{mSPa}} \mathbf{1 0}^{10}(\mathrm{~g} / \\
\end{array}$} & \multicolumn{3}{|c|}{ Mechanical Properties ${ }^{d}$} \\
\hline & & & & TS (MPa) & E $(\%)$ & YM (MPa) \\
\hline Control film & $0.11 \pm 0.01^{\mathrm{a}}$ & $206 \pm 27^{\mathrm{a}}$ & $2.30 \pm 0.15^{\mathrm{a}}$ & $21 \pm 3^{\mathrm{a}}$ & $10 \pm 3^{b}$ & $131 \pm 19^{a}$ \\
\hline RH-film & $0.11 \pm 0.01^{\mathrm{a}}$ & $213 \pm 14^{\mathrm{a}}$ & $2.80 \pm 0.58^{\mathrm{a}}$ & $8 \pm 1^{\mathrm{c}}$ & $8 \pm 1^{\mathrm{b}}$ & $122 \pm 18^{\mathrm{a}}$ \\
\hline RHB-film & $0.11 \pm 0.01^{\mathrm{a}}$ & $185 \pm 12^{\mathrm{a}, \mathrm{b}}$ & $2.11 \pm 0.43^{\mathrm{a}, \mathrm{b}}$ & $12 \pm 2^{b}$ & $10 \pm 2^{\mathrm{b}}$ & $124 \pm 20^{\mathrm{a}}$ \\
\hline RHNF-film & $0.12 \pm 0.01^{\mathrm{a}}$ & $169 \pm 3^{b}$ & $1.80 \pm 0.10^{\mathrm{b}}$ & $18 \pm 3^{\mathrm{a}}$ & $15 \pm 1^{\mathrm{a}}$ & $54 \pm 12^{\mathrm{c}}$ \\
\hline
\end{tabular}

a,b,c- Different letters in the same column indicate significant differences $(\mathrm{p} \leq 0.05)$ between means (Tukey test). ${ }^{\mathrm{d}-} \mathrm{TS}=$ tensile strength; $\mathrm{E}=$ elongation; YM = Young's modulus.

\section{Conclusions}

$\mathrm{NaOH}$ pre-treatment followed by peracetic acid bleaching was effective at reducing the lignin content in rice hulls. The compact structure around the cellulosic fibers was removed, and the bundles were individualized. The extraction time did not affect the properties of the cellulose nanofibers, which demonstrated an increased crystallinity index (up to $70 \%$ ) and thermal stability than the raw material. Therefore, these materials could be produced after $1 \mathrm{~h}$ of hydrolysis (low energy consumption). The nanocellulose crystallized as interconnected webs of tiny nanofibers with diameters $<100 \mathrm{~nm}$ and lengths of several micrometers. These dimensions resulted in a wide range of aspect ratios.

\section{References}

1. Brinchi L, Cotana F, Fortunati E and Kenny JM. Production of nanocrystalline cellulose from lignocellulosic biomass: technology and applications. Carbohydrate Polymers. 2013; 94(1):154-169. http://dx.doi.org/10.1016/j.carbpol.2013.01.033.

2. Alemdar A and Sain M. Isolation and characterization of nanofibers from agricultural residue - wheat straw and soy hulls. Bioresource Technology. 2008; 99(6):1664-1671. http:// dx.doi.org/10.1016/j.biortech.2007.04.029.

3. Purkait BS, Ray D, Sengupta S, Kar T, Mohanty A and Misra M. Isolation of cellulose nanoparticles from sesame husk. Industrial and Engineering Chemistry Research. 2011; 50(2):871-876. http://dx.doi.org/10.1021/ie101797d.

4. Flauzino WP No, Silvério HA, Dantas NO and Pasquini D. Extraction and characterization of celulose nanocrystals from agroindustrial residue-soy hulls. Industrial Crops and Products. 2013; 42:480-488. http://dx.doi.org/10.1016/j.indcrop.2012.06.041.

5. Soltani N, Bahrami A, Pech-Canul MI and Gonzalez LA. Review on the physicochemical treatments of rice husk for production of advanced materials. Chemical Engineering Journal. 2015; 264:899-935. http://dx.doi.org/10.1016/j.cej.2014.11.056.

6. Dagnino EP, Chamorro ER, Romano SD, Felissia FE and Area MC. Optimization of the acid pretreatment of rice hulls to obtain fermentable sugars for bioethanol production. Industrial Crops and Products. 2013; 42:363-368. http://dx.doi.org/10.1016/j. indcrop.2012.06.019.

7. Banerjee S, Sen R, Pandey RA, Chakrabarti T, Satpute D, Giri BS, et al. Evaluation of wet air oxidation as a pretreatment strategy for bioethanol production from rice husk and process optimization. Biomass and Bioenergy. 2009; 33(12):1680-1686. http://dx.doi.org/10.1016/j.biombioe.2009.09.001.

8. Satyanarayana KG, Arizaga GGC and Wypych F. Biodegradable composites based on lignocellulosic fibers - an overview.
The addition of $2.5 \%(\mathrm{w} / \mathrm{w})$ of the nanofibers to starch-glycerol films (produced by extrusion) resulted in the opacity, water vapor permeability and improved mechanical properties of starch films. These results suggest that this renewable source of agro-industrial residue has promise as a reinforcing agent in polymer composites.

\section{Acknowledgements}

The authors wish to thank the Laboratory of Microscopy and Microanalysis (LMEM) and the Laboratory of X-Ray Diffraction (LARX) - State University of Londrina for the analyses, and CNPq - Brazil (No. 479768-2012-9) for financial support.

Progress in Polymer Science. 2009; 34(9):982-1021. http:// dx.doi.org/10.1016/j.progpolymsci.2008.12.002.

9. Abdul Khalil HP, Bhat AH and Ireana Yusra AF. Green composites from sustainable cellulose nanofibrils: a review. Carbohydrate Polymers. 2012; 87(2):963-979. http://dx.doi.org/10.1016/j. carbpol.2011.08.078.

10. Abdul-Khalil HP, Davoudpour Y, Nazuruyl Islam M, Asniza M, Sudesh K, Dungani R, et al. Production and modification of nanofibrillated cellulose using various mechanical processes: a review. Carbohydrate Polymers. 2014; 99:649-665. http:// dx.doi.org/10.1016/j.carbpol.2013.08.069.

11. Janoobi M, Harun J, Shakeri A, Misra M and Oksman K. Chemical composition, crystallinity and thermal degradation of bleached and unbleached kenaf bast (Hibiscus cannabinus) pulp and nanofiber. BioResources. 2009; 4(2):626-639.

12. Hassan ML, Mathew AP, Hassan EA, El-Wakil NA and Oksman K. Nanofibers from bagasse and rice straw: Process optimization and properties. Wood Science and Technology. 2010; 46:193205. http://dx.doi.org/10.1007/s00226-010-0373-z.

13. Ferrer A, Filpponen I, Rodríguez A, Laine J and Rojas OJ. Valorization of residual Empty Palm Fruit Bunch Fibers (EPFBF) by microfluidization: production of nanofibrillated cellulose and EPFBF nanopaper. Bioresource Technology. 2012; 125:249-255. http://dx.doi.org/10.1016/j.biortech.2012.08.108.

14. Qua EH, Hornsby PR, Sharma HS and Lyons G. Preparation and characterisation of cellulose nanofibers. Journal of Materials Science. 2011; 46(18):6029-6045. http://dx.doi.org/10.1007/ s10853-011-5565-X.

15. Abraham E, Deepa B, Pothan LA, Jacob M, Thomas S, Cvelbar $\mathrm{U}$, et al. Extraction of nanocellulose fibrils from lignocellulosic fibres: a novel approach. Carbohydrate Polymers. 2011; 86(4):1468-1475. http://dx.doi.org/10.1016/j.carbpol.2011.06.034.

16. Paschoal G, Muller CM, Carvalho GM, Tischer CA and Mali S. Isolation and characterization of nanofibrillated cellulose 
from oat hulls. Quimica Nova. 2015; 38(4):478-482. http:// dx.doi.org/10.5935/0100-4042.20150029.

17. Kaushik A, Singh M and Verma G. Green nanocomposites based on thermoplastic starch and steam exploded cellulose nanofibrils from wheat straw. Carbohydrate Polymers. 2010; 82(2):337-345. http://dx.doi.org/10.1016/j.carbpol.2010.04.063.

18. Siqueira G, Bras J and Dufresne A. Cellulosic bionanocomposites: a review of preparation, properties and applications. Polymers. 2010; 2(4):728-765. http://dx.doi.org/10.3390/polym2040728.

19. Ng HM, Sin LT, Tee TT, Bee ST, Hui D, Low CY, Rahmat AR. Extraction of cellulose nanocrystals from plant sources for application as reinforcing agent in polymers. Composites Part B. 2015; 75:176-200. http://dx.doi.org/10.1016/j. compositesb.2015.01.008.

20. Hietala M, Mathew AP and Oksman K. Bionanocomposites of thermoplastic starch and cellulose nanofibers manufactured using twin-screw extrusion. European Polymer Journal. 2013; 49(4):950-956. http://dx.doi.org/10.1016/j.eurpolymj.2012.10.016.

21. Association of Official Analytical Chemists - AOAC. Official Methods of Analysis of the Association of Official Analytical Chemists. 14th ed. Washington: AOAC; 2003.

22. American Association of Cereal Chemists-AACC. Approved Methods of the American Association of Cereal Chemists. 8th ed. St. Paul Minnesota: AACC; 1990. http://dx.doi.org/10.1002/ star.19890411114.

23. Updegraff DM. Semi-micro determination of cellulose in biological materials. Analytical Biochemistry. 1969; 32:420424.

24. Technical Association of the Pulp and Paper Industry - TAPPI. Tappi Test Method T222 om-88, Acid-insoluble lignin in wood and pulp. Atlanta: Tappi Press; 1999.

25. Chawla R and Patil GR. Soluble dietary fiber. Comprehensive Reviews in Food Science and Food Safety. 2010; 9(2):178-196. http:// dx.doi.org/10.1111/j.1541-4337.2009.00099.x.

26. Teodoro KB, Teixeira EM, Corrêa AC, Marconcini JM and Mattoso LH. Whiskers de fibra de sisal obtidos sob diferentes condições de hidrólise ácida: efeito do tempo e da temperatura de extração. Polímeros. 2011; 21(4):280-285.

27. Segal L, Creely JJ, Martin AE Jr and Conrad CM. An empirical method for estimating the degree of crystallinity of nature cellulose using the x-ray diffractometer. Textile Research Journal. 1959; 29:786-794.
28. Sobral PJ. Influência da espessura de biofilmes feitos à base de proteínas miofibrilares sobre suas propriedades funcionais. Pesquisa Agropecuaria Brasileira. 2000; 35(6):1-14.

29. American Society for Testing and Materials - ASTM. ASTM E9600: standard test methods for water vapor transmission of material. Philadelphia: ASTM; 2000.

30. American Society for Testing and Materials - ASTM. ASTM D882-91: standard test methods for tensile properties of thin plastic sheeting. Philadelphia: ASTM; 1996.

31. Patel M, Karera A and Prasanna P. Effect of thermal and chemical treatments on carbon and silica contents in rice husk. Journal of Materials Science. 1987; 22(7):2457-2464.

32. Liou TZ. Evolution of chemistry and morphology during the carbonization and combustion of rice husk. Carbon. 2004; 42(4):785-794. http://dx.doi.org/10.1016/j.carbon.2004.01.050.

33. Gürsoy N and Dayioğlu H. Evaluating peracetic acid bleaching of cotton as an environmentally safe alternative to hypochlorite bleaching. Textile Research Journal. 2000; 70(6):475-480. http://dx.doi.org/10.1177/004051750007000602.

34. Krizman P, Kovac F and Tavcer P. Bleaching of cotton fabric with peracetic acid in the presence of different activators. Coloration Technology. 2005; 121(6):304-309. http://dx.doi. org/10.1111/j.1478-4408.2005.tb00373.x.

35. El-Shafie A, Fouda MM and Hashem M. One-step process for bio-scouring and peracetic acid bleaching of cotton fabric. Carbohydrate Polymers. 2009; 78(2):302-308. http://dx.doi. org/10.1016/j.carbpol.2009.04.002.

36. Johar N, Ahmada I and Dufresne A. Extraction, preparation and characterization of cellulose fibres and nanocrystals from rice husk. Industrial Crops and Products. 2012; 37(1):93-99. http://dx.doi.org/10.1016/j.indcrop.2011.12.016.

37. Sun JX, Sun XF, Zhao H and Sun RC. Isolation and characterization of cellulose from sugarcane bagasse. Polymer Degradation \& Stability. 2004; 84(2):331-339. http://dx.doi.org/10.1016/j. polymdegradstab.2004.02.008.

38. Deepa B, Abraham E, Cherian BM, Bismarck A, Blaker JJ, Pothan LA, et al. Structure, morphology and thermal characteristics of banana nano fibers obtained by steam explosion. Bioresource Technology. 2011; 102(2):1988-1997. http://dx.doi.org/10.1016/j. biortech.2010.09.030.

39. Morán JI, Alvarez VA, Cyras VA and Vázquez A. Extraction of cellulose and preparation of nanocellulose from sisal fibers. Cellulose (London, England). 2008; 15(1):149-159. http:// dx.doi.org/10.1007/s10570-007-9145-9. 